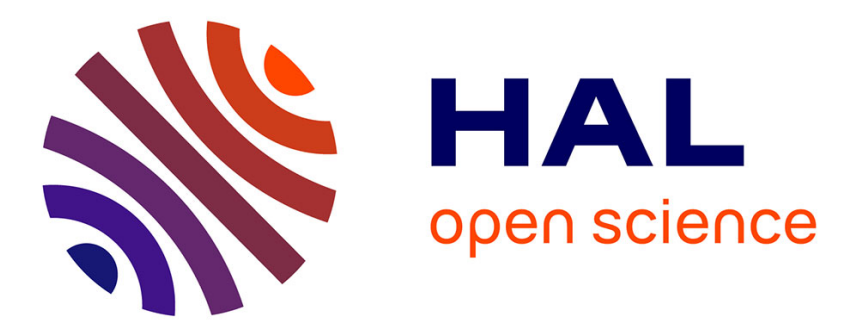

\title{
Application of shrinking core model to the adsorption of oxytetracycline onto peanut hull-derived activated carbon in a closed-loop fixed-bed reactor
}

\author{
D. Djedouani, M. Chabani, Abdeltif Amrane, A Bensmaili
}

\section{- To cite this version:}

D. Djedouani, M. Chabani, Abdeltif Amrane, A Bensmaili. Application of shrinking core model to the adsorption of oxytetracycline onto peanut hull-derived activated carbon in a closedloop fixed-bed reactor. Desalination and Water Treatment, 2016, 57 (30), pp.14304-14314. 10.1080/19443994.2015.1063458 . hal-01299898

HAL Id: hal-01299898

https://hal-univ-rennes1.archives-ouvertes.fr/hal-01299898

Submitted on 31 May 2016

HAL is a multi-disciplinary open access archive for the deposit and dissemination of scientific research documents, whether they are published or not. The documents may come from teaching and research institutions in France or abroad, or from public or private research centers.
L'archive ouverte pluridisciplinaire HAL, est destinée au dépôt et à la diffusion de documents scientifiques de niveau recherche, publiés ou non, émanant des établissements d'enseignement et de recherche français ou étrangers, des laboratoires publics ou privés. 


\title{
Application of shrinking core model to the adsorption of oxytetracycline onto peanut's hull derived activated carbon in a closed loop fixed bed reactor
}

\author{
D. Djedouani ${ }^{\mathrm{a}, *}$, M. Chabani ${ }^{\mathrm{a}}$, A. Amrane ${ }^{\mathrm{b}}$, A. Bensmaili $^{\mathrm{a}}$
}

${ }^{a}$ Faculty of Chemical Engineering, USTHB, Algiers, Algeria. Tel. +213 21207767; emails: ddjedouani@usthb.dz (D. Djedouani), 5 mchabani_fr@yahoo.fr (M. Chabani), abensmaili@yahoo.fr (A. Bensmaili)

${ }^{b}$ Ecole Nationale Supérieure de Chimie de Rennes, CNRS, UMR6226, Avenue du Général Leclerc, CS 50837, 35708 Rennes Cedex

7, France, email: abdeltif.amrane@univ-rennes1.fr

\begin{abstract}
In the present paper, the ability of peanut's hull-derived activated carbon $\mathrm{AC}(\mathrm{PH}-800)$ to adsorb oxytetracycline (OTC) was investigated using batch adsorption with fixed-bed reactor. The factors influencing adsorption, such as contact time and sorbent concentration, were evaluated. Sorption kinetic and equilibrium data of OTC sorption onto AC(PH-800) were submitted to kinetics and equilibrium models in order to calculate the adsorption constant rate and the maximum capacity of the sorbent. The application of shrinking core model (SCM) for the removal of OTC was investigated with two assumptions finite and infinite volume solution. Oxytetracycline adsorption increased for increasing initial OTC concentrations, and equilibrium isotherms can be accurately described by the Freundlich equation. Experimental data were analyzed using the SCM and the analysis based on statistical and graphical method proved that the adsorption followed the product layer diffusion controlled equation of the model. The approach modeling considering a finite volume solution assumption was more successful than the modeling approach involving an infinite volume solution.
\end{abstract}

Keywords: Oxytetracycline; Sorption mechanism; Activated carbon; Activation; Carbonization

\section{Introduction}

Water pollution is one among the many threats that the world population is facing and which requires immediate attention. Moreover, micropollutant contamination is confirmed by the frequent detection of organic compounds such as antibiotics (i.e. oxytetracycline) in surface, ground, and wastewaters [1]. About 150 tons of high concentration wastewater is produced in the oxytetracycline (OTC) production and this kind of wastewater is hard to eliminate by traditional wastewater procedures. Among the numerous techniques for reducing the amount of OTC, adsorption was found to be one of the simplest and most effective techniques [2].

Adsorption is widely used as it is among the most effective and relatively inexpensive methods in the treatment processes. Highly porous adsorbents with good selectivity such as activated carbon have shown excellent ability as effective adsorbents for the removal of many aqueous contaminants, both organic and inorganic, such as antibiotics (i.e. oxytetracycline) and 
certain metal ions [3]. The high adsorption capacity of activated carbon is a result of its high surface area, extensive porosity in the interior of the particles, and presence of many different types of surface functional groups.

A challenge in the field of activated carbon production is to produce specific materials with given properties including surface area and porosity from low-cost precursors and at low temperatures [4]. Currently, there are many studies on the development of low-cost adsorbents, namely using waste materials for this purpose. Despite the satisfactory results obtained using some of these low-cost adsorbents, ACs are known to be more efficient in adsorbing a greater amount of pollutants. AC production costs can be reduced by either choosing a cheap raw material or by applying a proper production method [5]. In order to increase its adsorption capacity, the pore network should be developed during AC preparation by application of adequate physical (PhA) or chemical (ChA) treatments. The use of ChA seems to be more frequent in the preparation of $\mathrm{AC}$ from agricultural wastes and the most frequently used agents are $\mathrm{H}_{3} \mathrm{PO}_{4}, \mathrm{KOH}$, and $\mathrm{ZnCl}$ [3].

Only few studies have determined the possibility of using activated carbons prepared from agricultural wastes for antibiotics oxytetracycline removal [6-8]. Therefore, the present work evaluates the preparation, characterization, and the use of activated carbons from peanut's hull as alternate adsorbents for oxytetracycline removal from aqueous solutions in closed fixedbed reactor. Furthermore, modeling of kinetics data was conducted in order to contribute to describe the sorption of the pollutant on the adsorbent material. Among the available models to develop the rate expression for fluid-solid reaction, the shrinking core model (SCM) has been widely used; it is the main model that has been developed for non-catalytic fluidsolid reactions. It has been well established that the SCM is the best and simplest representation for the majority of non-catalytic fluid-solid system [9-11].

For a more realistic approach and by referring to the electron microscopy image of the prepared activated carbon, the solid particle may be considered as cylindrical, remains unchanged in size during reaction and it reacts with the fluid isothermally. The rate expressions have been developed for such solid particle in this work.

Furthermore, in its original form [12], the assumption of constant and uniform bulk concentration of $A$ in the fluid phase is made. This is similar to the infinite solution volume concept used in the analysis of adsorption and ion-exchange kinetics. In this study, the more general solutions are presented, i.e. for changing fluid concentration (finite solution volume). Also, the concentration of the reacting fluid is assumed to be constant or changing.

The kinetics was fitted to the SCM with the two assumptions of the finite and the infinite solution volume. The purpose of this report is to take into account the effect of finite bulk liquid on dissolution.

Despite good performance and detailed studies on the kinetics adsorption of oxytetracycline onto activated carbon, up to now, to the best of our knowledge, no detailed studies of the application of the SCM with the assumption of the infinite solution volume for cylindrical particles are reported in the literature. Some kinetics have been presented for the oxytetracycline-activated carbon adsorption process by various authors [6-8], but for SCM detailed kinetic data are still unknown.

\section{Theory}

\subsection{Equilibrium modeling}

The sorption equilibrium data are conveniently represented by sorption isotherms. Adsorption isotherms are basic requirement for designing any adsorption system, which correspond to the relationship between the mass of the solute sorbed per unit mass of sorbent $q_{e}$ and the solute concentration for the solution at equilibrium $C_{e}$. The sorption isotherms were investigated using two equilibrium models; the Langmuir and Freundlich isotherms models.

The Langmuir equation (Eq. (1)) describes the adsorption of gas molecules on a planar surface [13].

$$
\frac{C_{e} b Q_{0}}{1+b C_{e}}
$$

The empirical Freundlich model can be applied to non-ideal adsorption on heterogeneous surfaces as well as multilayer adsorption and is expressed by the following equation [14]:

$q_{e}=K_{\mathrm{F}} \cdot C_{e}^{1 / n}$

where $q_{e}\left(\mathrm{mg} \mathrm{g}^{-1}\right)$ and $C_{e}\left(\mathrm{mg} \mathrm{l}^{-1}\right)$ are the amount of adsorbed OTC per unit weight of AC(PH-800) and unadsorbed OTC concentration in solution at equilibrium, respectively. $Q_{0}$ is the maximum adsorption capacity $\left(\mathrm{mg} \mathrm{g}^{-1}\right)$ and $b$ is a constant related to the affinity of the binding sites. $K_{\mathrm{F}}$ and $1 / n$ are the Freundlich constants characteristic of the system, indicating adsorption capacity and intensity, respectively. 
To interpret the kinetic experimental data of an organic pollutant, it is necessary to determine the adsorption/desorption process steps in a given experimental system which govern the overall

10 adsorption/desorption rate. A wide variety of situations indicates that the unreacted-core model approximates real particles more closely in most cases than does the progressive-conversion model. Since the unreacted-core model seems to reasonably 15 represent the reality in a wide variety of situations and in order to investigate the mechanism of sorption, the experimental data were analyzed using the SCM.

\subsubsection{The SCM development for cylindrical particle}

The SCM has been derived for non-catalytic solidfluid reactions [12]; it considers the heterogeneous reaction between a solid and a fluid phase:

$A$ (fluid) $+b \cdot B($ solid $) \rightarrow$ products

The overall rate is a combination of the diffusion rate of $A$ in the fluid film, the diffusion rate of $A$ in the solid, and the chemical reaction rate. The reaction occurs first at the outer skin of the solid particle. Then, progressively, the reaction zone moves into the solid, leaving behind completed concerted solid (ash) [12].

30 Consequently, at any time there exists an unreacted core of the solid, which shrinks in size during the reaction.

By referring to Fig. 2, we assume that the solid particle is cylindrical, remains unchanged in size dur-

35 ing reaction, and it reacts with the fluid isothermally. In all equations, the fractional conversion $X_{B}$ is used and the rate equations can be written as discussed below [12,15-18].

2.2.1.1. When diffusion through liquid film controls. Whenever the resistance of the liquid film controls, the concentration driving force, given by $C_{A L}-C_{A S}$, remains constant during reaction of cylindrical particle; with $C_{\mathrm{AL}}$ and $C_{\mathrm{AS}}$ represent the concentrations of solute in the bulk liquid phase and at the solid-liquid interface, $\mathrm{d} N_{B}=b \mathrm{~d} N_{A}$, can be written:

$$
\begin{aligned}
\frac{1}{S_{\mathrm{ex}} \frac{\mathrm{d} N_{B}}{\mathrm{~d} t}} & =-\frac{1}{2 \pi R H} \frac{\mathrm{d} N_{B}}{\mathrm{~d} t}=-\frac{b}{2 \pi R H} \frac{\mathrm{d} N_{B}}{\mathrm{~d} t} \\
& =b k_{L}\left(C_{\mathrm{AL}}-C_{\mathrm{AS}}\right)=b k_{l} C_{\mathrm{AL}}
\end{aligned}
$$

If $\rho_{B}$ is the molar density of $B$ in the solid and $V$ the volume of a cylindrical particle, the amount of $B$ present in particle is:

$N_{B}=\rho_{B} V=\left(\frac{\text { moles } B}{\mathrm{~cm}^{3} \text { solid }}\right)\left(\mathrm{cm}^{3}\right.$ solid $)$

The decrease in volume or radius of unreacted core accompanying the disappearance of $\mathrm{d} N_{B}$ moles of solid reactant or $b \mathrm{~d} N_{A}$ moles of fluid reactant is then given by

$$
\begin{aligned}
-\mathrm{d} N_{B} & =-b \mathrm{~d} N_{\mathrm{A}}=-\rho_{B} \mathrm{~d} V=-\rho_{B} \mathrm{~d}\left(\pi r_{c}^{2} H\right) \\
& =-2 \pi H \rho_{B} r_{c} \mathrm{~d} r_{c}
\end{aligned}
$$

Replacing (Eq. (6)) in (Eq. (4)) gives the rate of reaction in terms of the shrinking radius of unreacted core, or

$$
\frac{\rho_{B}}{R} r_{c} \frac{\mathrm{d} r_{c}}{\mathrm{~d}} t=b k_{l} C_{\mathrm{AL}}
$$

where $k_{1}$ is the mass transfer coefficient between fluid and particle; rearranging and integrating, we find how the uncreated core shrinks with time.

(1) Constant bulk concentration

If the volume of the bulk liquid phase $V$ is large enough, the concentration of solute $C_{\mathrm{AL}}$ in the bulk liquid phase is essentially constant. Thus

$-\frac{\rho_{B}}{R} \int_{R}^{r_{c}} r_{c} d r_{c}=b k_{l} C_{\mathrm{AL}} \int_{0}^{t} d t$

After integrating (Eq. (8)) we obtain:

$t=\frac{R \rho_{B}}{2 b k_{l} C_{\mathrm{AL}}}\left[1-\left(\frac{r_{c}}{R}\right)^{2}\right]$

\section{(2) Variable bulk concentration}

If the volume of the bulk liquid phase is finite, the variation of the bulk liquid concentration is $C_{\mathrm{AL}}$. Thus, integrating of (Eq. (8)) leads to:

$-\frac{\rho_{B}}{R} \int_{R}^{r_{c}} r_{c} d r_{c}=b k_{l} \int_{0}^{t} C_{\mathrm{AL}} d t$ 
Or

$\int_{0}^{t} C_{A L} d t=\frac{R \rho_{B}}{2 b k_{l}}\left[1-\left(\frac{r_{c}}{R}\right)^{2}\right]$

Eqs. (9) and (11) can be written in terms of fractional conversion by noting that

$1-X_{B}=\left(\frac{\text { volume of unreacted core }}{\text { total volume of particle }}\right)=\frac{\pi r_{c}^{2} H}{\pi R^{2} H}=\left(\frac{r_{c}}{R}\right)^{2}$

Therefore

If the concentration of solute in the bulk liquid phase is essentially constant, the values of the rate constants $K_{m 1}$, can be calculated from the slope of the plot of $X_{B}$ against time (Eq. (13)).

$X_{B}=\frac{2 b k_{l} C_{\mathrm{AL}}}{R \rho_{B}} t=K_{m 1} t$

2.2.1.2. When the diffusion through inert/ash layer controls. To develop an expression between time and radius, such as (Eqs. (13) and (14)) for film resistance, the assumption that the shrinkage of the unreacted core is slower than the flow rate of A toward the unreacted core allows great simplification in the mathematical relations which follows. With this assumption, the rate of reaction of $A$ at any instant is given by its rate of diffusion to the reaction surface, or

$-\frac{\mathrm{d} N_{A}}{\mathrm{~d} t}=2 \pi r H Q_{A}=2 \pi R H Q_{A}=2 \pi r_{C} H Q_{A}$

For convenience, let the flux of $A$ within the ash layer be expressed by the Fick's law. Then noting that both $Q_{A}$ and $\mathrm{d} C_{\mathrm{AL}} / \mathrm{d} r$ are positive, we have

$Q_{A}=D_{e} \frac{\mathrm{d} C_{\mathrm{AL}}}{\mathrm{d} r}$ where $D_{e}$ is the effective diffusion coefficient of liquid reactant in the ash layer. Combining (Eqs. (15) and (16)), we obtain for any $r$

$-\frac{\mathrm{d} N_{A}}{\mathrm{~d} t}=2 \pi r_{c} H D_{e} \frac{\mathrm{dC}_{\mathrm{AL}}}{\mathrm{d} r}$

Integrating across the ash layer from $R$ to $r_{c}$ we obtain

$-\frac{\mathrm{d} N_{A}}{\mathrm{~d} t} \int_{R}^{r_{c}} \frac{\mathrm{d} r}{r}=2 \pi H D_{e} \int_{C_{\mathrm{AL}}}^{C_{\mathrm{AC}=0}} \mathrm{~d} C_{\mathrm{AL}}$

Or

$-\frac{\mathrm{d} N_{A}}{\mathrm{~d} t}\left(\ln \frac{r_{c}}{R}\right)=2 \pi H D_{e} C_{\mathrm{AL}}$

This expression represents the conditions of a reacting cylindrical particle at any time. As with film diffusion, let us eliminate $N_{A}$ by writing it in terms of $r_{c}$. This relation is given by (Eq. (7)); hence replacing in (Eq. (19)), separating variables, and integrating, we obtain

$-\rho_{B} \int_{R}^{r_{c}} r \ln \left(\frac{r}{R}\right) d r=b D_{e} \int_{0}^{t} C_{\mathrm{AL}} d t$

(1) For constant bulk concentration

It can be shown that in the case of constant bulk concentration, integrating (Eq. (20)) and Substituting (Eq. (12)) we obtain

$t=\frac{\rho_{B} R^{2}}{4 b C_{\mathrm{AL}} D_{e}}\left[X_{B}+\left(1-X_{B}\right) \ln \left(1-X_{B}\right)\right]$

Or

$\left[X_{B}+\left(1-X_{B}\right) \ln \left(1-X_{B}\right)\right]=k_{d 1} t$

If the concentration of solute in the bulk liquid phase is essentially constant, the values of the rate constants $K_{d 1}$, is calculated from the slope of the plot of $f\left(X_{B}\right)$ against time (Eq. (22)).

(2) Variable bulk concentration

For the case of variable bulk concentration, integrating of (Eq. (20)) and the Substituting (Eq. (12)) 65 gives 
Table 1

Different equation rate forms for the shrinking core mechanism model onto cylindrical particle

\begin{tabular}{|c|c|c|}
\hline & Equations rate forms & \\
\hline & Constant bulk concentration & Variable bulk concentration \\
\hline $\begin{array}{l}\text { Diffusion through liquid } \\
\text { film controls }\end{array}$ & $\begin{array}{l}X_{B}=K_{m 1} t \quad E q \cdot(13) \\
K_{m 1}=\frac{2 b k_{l} C_{\mathrm{AL}}}{R \rho_{B}}\end{array}$ & $\begin{array}{l}X_{B}=K_{m 2} \int_{0}^{t} C_{\mathrm{AL}} t \quad E q .(14) \\
K_{m 2}=\frac{2 b k_{l}}{R \rho_{B}}\end{array}$ \\
\hline $\begin{array}{l}\text { Diffusion through inert/ } \\
\text { ash layer controls }\end{array}$ & $\begin{array}{l}{\left[X_{B}+\left(1-X_{B}\right) \ln \left(1-X_{B}\right)\right]=k_{d 1} t \quad E q .(22)} \\
k_{d 1}=\frac{4 b C_{\mathrm{AL}} D_{e}}{\rho_{B} R^{2}}\end{array}$ & $\begin{array}{l}{\left[X_{B}+\left(1-X_{B}\right) \ln \left(1-X_{B}\right)\right]=k_{d 2} \int_{0}^{t} C_{\mathrm{AL}} d t \quad E q \cdot(24)} \\
k_{d 2}=\frac{4 b D_{e}}{\rho_{B} R^{2}}\end{array}$ \\
\hline Chemical reaction controls & $\begin{array}{l}1-\left(1-X_{B}\right)^{1 / 2}=K_{1} t \quad \text { Eq.(29) } \\
K_{1}=\frac{b k_{s} C_{\mathrm{AL}}}{\rho_{B} R}\end{array}$ & $\begin{array}{l}1-\left(1-X_{B}\right)^{1 / 2}=K_{2} \int_{0}^{t} C_{\mathrm{AL}} t \quad(30) \\
K_{2}=\frac{b k_{s}}{\rho_{B} R}\end{array}$ \\
\hline
\end{tabular}

$\int_{0}^{t} C_{\mathrm{AL}} d t=\frac{\rho_{B} R^{2}}{4 b D_{e}}\left[X_{B}+\left(1-X_{B}\right) \ln \left(1-X_{B}\right)\right]$

Or

$$
\left[X_{B}+\left(1-X_{B}\right) \ln \left(1-X_{B}\right)\right]=k_{d 2} \int_{0}^{t} C_{\mathrm{AL}} d t
$$

5 If the volume of the bulk liquid phase is finite, the values of the rate constants $k_{d 2}$ are calculated from the slope of the plot of $f\left(X_{B}\right)$ against $\int_{0}^{t} C_{\mathrm{AL}} d t$ (Eq. (24)).

2.2.1.3. When the chemical reaction controls. Since the progress of the reaction is unaffected by the presence of any ash layer, the quantity of reacting material is proportional to the available surface of unreacted core. Thus, based on unit surface of unreacted core, the rate of reaction for the stoichiometry of (Eq. (3)) is

$-\frac{1}{2 \pi r_{C} H} \frac{\mathrm{d} N_{B}}{\mathrm{~d} t}=-\frac{b}{2 \pi r_{c} H} \frac{\mathrm{d} N_{A}}{\mathrm{~d} t}=b k_{s} C_{\mathrm{AL}}$

where $k_{s}$ is the first-order rate constant for the surface reaction. Writing $N_{B}$ in terms of the shrinking radius, as given in (Eq. (6)), we obtain

$-\frac{1}{2 \pi r_{c} H} 2 \pi H \rho_{B} r_{c} \frac{\mathrm{d} r_{c}}{\mathrm{dt}}=-\rho_{B} \frac{\mathrm{d} r_{c}}{\mathrm{dt}}=b k_{s} C_{\mathrm{AL}}$

Which on integration becomes

(1) For constant bulk concentration

The integration of (Eq. (26)) for the assumption of constant bulk concentration gives

$$
-\rho_{B} \int_{R}^{r_{c}} d r_{c}=b k_{s} C_{\mathrm{AL}} \int_{0}^{t} d t
$$

Or

$t=\frac{\rho_{B}}{b k_{s} C_{\mathrm{AL}}}\left(R-r_{c}\right)=\frac{\rho_{B} R}{b k_{s} C_{\mathrm{AL}}}\left(1-\frac{r_{c}}{R}\right)$

In terms of fractional conversion we obtain

$$
1-\left(1-X_{B}\right)^{1 / 2}=\frac{b k_{s} C_{\mathrm{AL}}}{\rho_{B} R} t=K_{1} t
$$

(2) For variable bulk concentration

$1-\left(1-X_{B}\right)^{1 / 2}=\frac{b k_{s}}{\rho_{B} R} \int_{0}^{t} C_{\mathrm{AL}} d t=K_{2} \int_{0}^{t} C_{\mathrm{AL}} d t$

The values of the rate constants $K_{1}$ and $K_{2}$ are calculated from the slope of the plot of $f\left(X_{B}\right)$ against, time and $\int_{0}^{t} C_{\mathrm{AL}} d t$, respectively.

The straight line plots of $f\left(X_{B}\right)$ against $t$ or $\int_{0}^{t} C_{\mathrm{AL}} d t$ have been employed to obtain rate parameters. The function $f\left(X_{B}\right)$ is different for each controlling mechanism. The following table summarizes the different equation rate forms for each model (Table 1).

\section{Experimental}

\subsection{Preparation of activated carbon}

A local south Algerian peanut's hull was used as the starting material serving as precursor to produce activated carbon. Peanut's hull was washed with water and reduced in size by hammer milling prior to experiments. A particle size range of $50-250 \mu \mathrm{m}$ was used throughout the present study. Chemical activation was performed with strong dehydrating agent. The activated agent of choice was: the orthophosphoric acid. In 
Table 2

Oxytetracycline properties

\begin{tabular}{llll}
\hline Solute & Formula & Molecular weight & $\mathrm{p} K_{\mathrm{a}}$ \\
\hline Oxtetracycline & $\mathrm{C}_{22} \mathrm{H}_{24} \mathrm{~N}_{2} \mathrm{O}_{9}$ & $460.4 \mathrm{~g}$ & $\mathrm{p} K_{\mathrm{a} 1}=3.27 ; \mathrm{p} K_{\mathrm{a} 2}=7.32$ et $\mathrm{p} K_{\mathrm{a} 3}=9.11$ \\
\hline
\end{tabular}

this procedure, carbonization was performed at $800^{\circ} \mathrm{C}$ for $2 \mathrm{~h}$. The $\mathrm{AC}$ was washed adequately with deionizer water, and was also dried at $105^{\circ} \mathrm{C}$ for $6.0 \mathrm{~h}$ to constant weight for further analysis and characterization. The activated carbonaceous material obtained from peanut's hull was called $\mathrm{PH}-800$.

\subsection{Oxytetracycline solutions preparation}

Oxytetracycline formula and physicochemical properties are depicted in Table 2 [19]. OTC solutions are prepared in distilled water. Moreover, stock solutions should be stored at $2-8^{\circ} \mathrm{C}$ in the dark for no longer than one month because OTC hydrolyzes in aqueous solution and it is light sensitive. OTC molecule presents three acido-basic moieties with specific $\mathrm{p} K_{\mathrm{a}}$. So this substance could bear different charges depending on the solution $\mathrm{pH}$.

\subsection{Sorption procedure: fixed-bed experiments}

Fixed-bed operations are widely used in pollution control processes such as separating ions by ion-exchange bed or removing toxic organic compounds by carbon adsorption bed [20]. All fixed-bed closed experiments utilized a glass column of $50 \mathrm{~cm}$ length and $2 \mathrm{~cm}$ internal diameter into which the derived activated carbon adsorbent was packed. The adsorbent bed was supported by glass wool and glass beads to ensure uniform liquid distribution. The column was operated in an up flow mode. A pump was used to control the flow rate at the inlet. Samples were collected periodically from storage tank and analyzed for the remaining OTC concentration $\left(C_{t}\right)$. The flow through the column was continued until the OTC concentration reached equilibrium in the storage tank. Fig. 1 represents the experimental device.

The results obtained using closed fixed-bed indicated that the protocol of contact between coal and the solution was especially efficient for kinetic monitoring. The following equation was used to compute the specific uptake by the sorbent $q_{t}\left(\mathrm{mg} \mathrm{g}^{-1}\right.$ of dry solid):

$q_{t}=\frac{\left(C_{o}-C_{t}\right)}{V} m$

where $V(\mathrm{~L})$ is the solution volume and $m(\mathrm{~g})$ the amount of dry sorbent $C_{o}$ and $C_{t}$ are the initial OTC concentration and its concentration at a given time $t$, respectively $\left(\mathrm{mg} \mathrm{L}^{-1}\right)$.

\section{Results and discussion}

\subsection{Characterization of derived activated carbon (PH-800)}

\subsubsection{Scanning electron microscopy}

A surface image of the sorbent and the saturated material was analyzed by scanning electron microscopy at different magnifications as shown in Fig. 2. As can be seen in Fig. $2\left(\mathrm{~A}_{1,2}\right)$, a clear pore

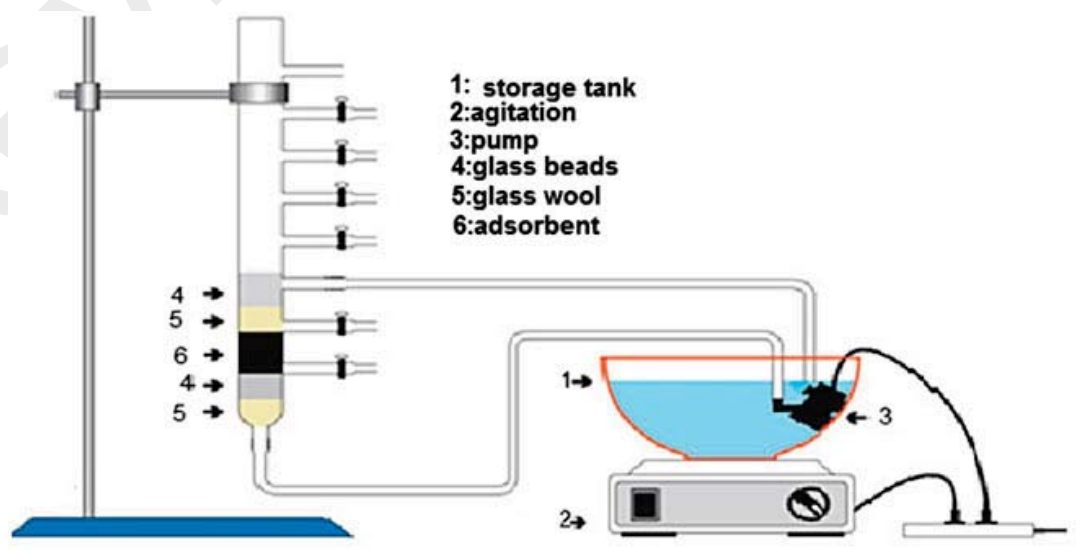

Fig. 1. Schematic illustration of the experimental apparatus. 

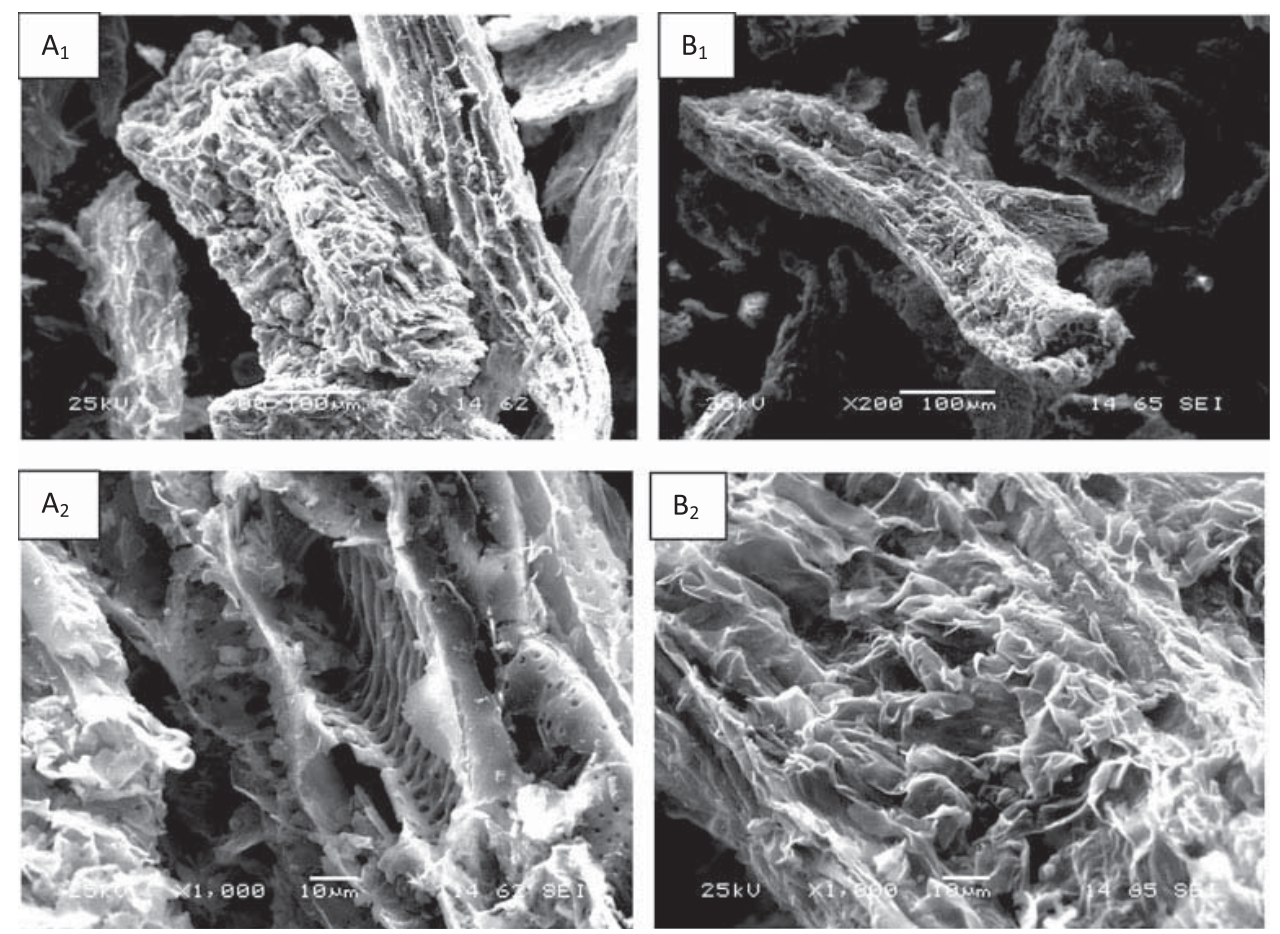

Fig. 2. MEB image of raw $\left(A_{1,2}\right)$ and saturated $\left(B_{1,2}\right)$ activated carbon at different magnifications.

structure was visible onto the raw material (PH-800). From Fig. 2( $\left.\mathrm{B}_{1,2}\right)$, it is possible to appreciate that the surface of the saturated $\mathrm{AC}(\mathrm{PH}-800)$ was covered by impurities and the pore structure could not be seen clearly.

\subsubsection{Porosity characterization}

Porosity describes the number of pores present in a sample. Porosity therefore enhances adsorption capacity of an adsorbent. The prepared activated carbon (PH-800) was subject to iodine number and the BET surface area. The iodine adsorption capacity is represented as iodine number, which indicates milligrams of iodine adsorbed by gram of activated carbon (PH-800), for testing acting activated carbon. The BET surface area and the average pore size distribution are estimated using the surface area analyzer. The average pore radius $r_{p}$ was estimated by applying the following equation [21]: $r_{p}=\frac{2 V}{S_{\mathrm{BET}}}$

where $V\left(\mathrm{~cm}^{3} \mathrm{~g}^{-1}\right)$ is the total pore volume and $S_{\mathrm{BET}}$ is the BET surface area. Table 3 summarizes the properties of the prepared activated carbon.

\subsection{Adsorption isotherms}

The isotherms of adsorption of OTC onto AC(PH$800)$ were performed in the range of $5-150 \mathrm{mg} \mathrm{L}^{-1}$ initial OTC concentrations. In this work, the Langmuir and Freundlich isotherm models were tested.

The data obtained by nonlinear fitting of the isotherm (Fig. 3 and Table 4) shows that the best isotherm model was the Freundlich isotherm that presented the highest $R^{2}$ value; from this as the adsorbate concentration increases, the concentration of adsorbate on the adsorbent surface also increases.

Table 3

Properties of AC(PH-800)

\begin{tabular}{llllll}
\hline & $\begin{array}{l}S_{\mathrm{BET}} \\
\left(\mathrm{m}^{2} \mathrm{~g}^{-1}\right)\end{array}$ & $\begin{array}{l}\text { Micropore volume } \\
\left(\mathrm{cm}^{3} \mathrm{~g}^{-1}\right)\end{array}$ & $\begin{array}{l}\text { Total pore volume } \\
\left(\mathrm{cm}^{3} \mathrm{~g}^{-1}\right)\end{array}$ & $\begin{array}{l}r_{p} \\
\left(\mathrm{~cm}^{3} \mathrm{~g}^{-1}\right)\end{array}$ & $\begin{array}{l}\text { Iodine number } \\
\left(\mathrm{mg} \mathrm{g}^{-1}\right)\end{array}$ \\
\hline CAPH800 & 481.45 & 0.19 & 0.304 & $1,263 \mathrm{E}-07$ & 2,286 \\
\hline
\end{tabular}




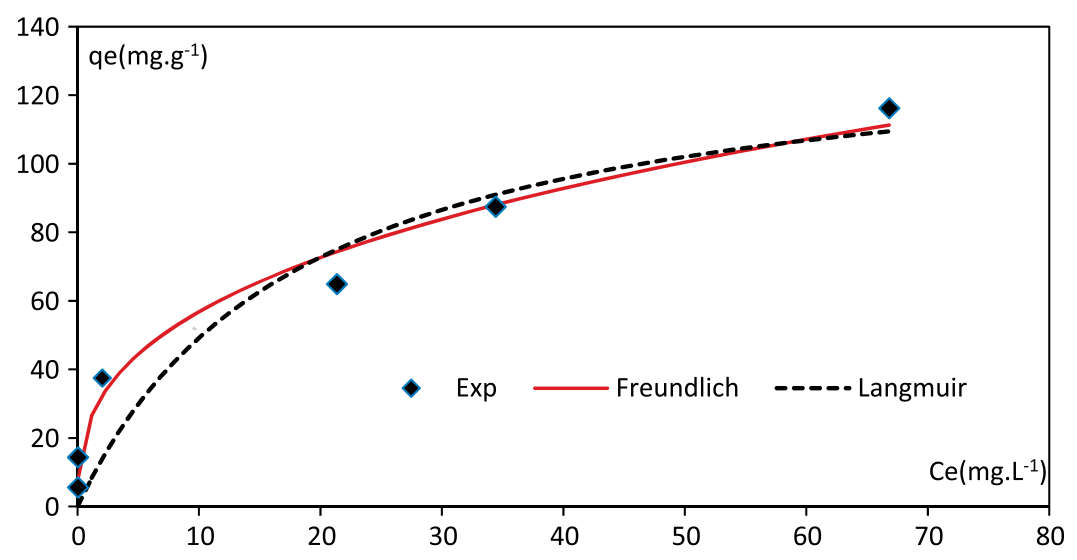

Fig. 3. Isotherm of adsorption of OTC onto AC(PH-800) fitted to Langmuir and Freundlich models.

Table 4

Data obtained from Freundlich and Langmuir isotherm models

\begin{tabular}{llll}
\hline Langmuir model & $Q_{0}$ & $b$ & $R^{2}$ \\
& 139.526 & 0.054 & 0.898 \\
& & & \\
Freundlich model & $K_{\mathrm{F}}$ & $n$ & $R^{2}$ \\
& 25.135 & 0.354 & 0.979 \\
\hline
\end{tabular}

$n$ can also represent the adsorption equilibrium constant whose reciprocal $(1 / n)$ is the indicative of adsorption intensity. Sorption is nonlinear if $n$ is significantly lower or higher than one. If $n$ is less than one, which is our case, sorption decreases with increasing aqueous concentration, and conversely sorption increases with increasing aqueous concentration when $n$ is greater than one [22]. These results are in agreement with other findings involv- ing the Freundlich isotherm to describe the behavior in aqueous solutions $[1,23]$.

\subsection{Effect of the initial concentration}

The effect of the initial concentration on the OTC sorption by $\mathrm{AC}(\mathrm{PH}-800)$ was investigated in the range of $5-150 \mathrm{mg} \mathrm{L}^{-1}$ initial OTC concentrations. The variation of the uptake values with time for various initial concentrations is depicted in Fig. 4. The uptake amount increased with increasing initial OTC concentrations up to $150 \mathrm{mg} \mathrm{L}^{-1}$. At lower OTC concentrations, solute concentrations to sorbent sites ratio is higher, which cause an increase in OTC removal [24]. At higher concentrations, lower adsorption yield is due to the saturation of adsorption sites. It could be noted that the results obtained show that the capacity increased with increasing initial concentrations; the adsorbent was therefore effective even at high concentrations.

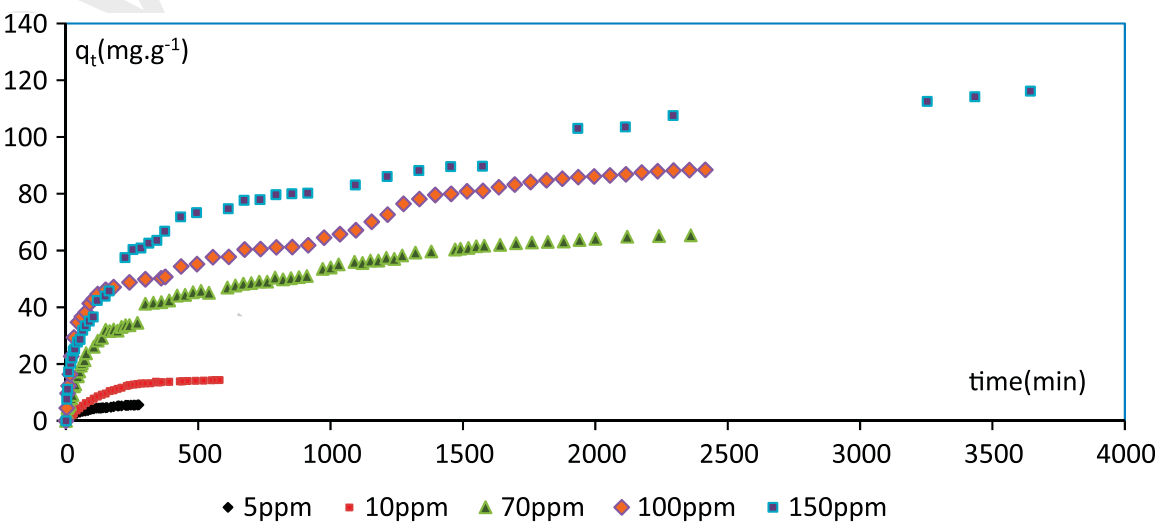

Fig. 4. Effect of the initial concentrations $\left(V=21, m_{\mathrm{AC}(\mathrm{PH}-800)}=1.5 \mathrm{~g} \mathrm{~L}^{-1}, T=22^{\circ} \mathrm{C}\right)$. 


\subsection{Kinetic modeling}

The equilibrium parameters in Table 4 were also applied in the uptake rate calculations since $X_{B}$ in the 5 kinetic model is the ratio of the loading capacity at any time during adsorption to the equilibrium loading capacity.

The analysis of the experimental data using the above equations (Eqs. (13), (22), and (29)) showed that the mechanism of OTC removal on $\mathrm{AC}(\mathrm{PH}-800)$ is complex and both the surface adsorption as well as intraparticle diffusion contributes to the actual adsorption process(linear portions of the curves do not pass through the origin; data not shown). The values of the rate constants and regression coefficients are shown in Table 5.

The fitting of the kinetics with the assumption of a finite solution volume(i.e. Eqs. (14), (24), and (30)) indicates that the mechanism of OTC removal on AC (PH-800) is controlled by liquid film diffusion (Eq. (14)) for the dilute concentration system; and the product layer diffusion (Eq. (24)) step for the remainder of the field concentration. The diffusion through inert/ash layer rate constant values (Table 6) decreased with increasing initial concentration of OTC with regression coefficients higher than 0.97 for all the entire adsorption period indicating that the rate-limiting step may be diffusion through inert/ash layer.

Zogorski et al. [25] indicated that external transport is the rate-limiting step in systems having poor mixing, dilute concentration of adsorbate (for OTC concentrations in the range of $5-10 \mathrm{mg} \mathrm{L}^{-1}$ ) (Table 6), small particle sizes of adsorbent, a high affinity of adsorbate for adsorbent. Some experiments conducted at low concentrations have shown that film diffusion controls the adsorption kinetics of low molecular weight substances $[26,27]$. The observed decrease in $R^{2}$ values with increasing initial adsorbate concentration can be explained by the growing effect of driving force. The concentration gradient, while the decrease in $R^{2}$ values at higher adsorbate concentrations, may be due to agglomeration of adsorbate particles which leads to a decrease in mass transfer resistance.

The experimental results show that the slope changes with initial concentration of OTC, at the same time, the regression coefficient $R^{2}$ for the high concentrations was high than for low concentration, which implies that the process involves more than one kinetic for the low concentrations.

Table 5

Values of the rate constants and regression coefficients for OTC sorption onto the AC(PH-800) (the infinite volume solution)

\begin{tabular}{|c|c|c|c|c|c|c|}
\hline \multirow[b]{2}{*}{$C_{0}(\mathrm{mg} / \mathrm{l})$} & \multicolumn{2}{|c|}{$\begin{array}{l}\text { Diffusion through liquid } \\
\text { film (Eq. (13)) }\end{array}$} & \multicolumn{2}{|c|}{$\begin{array}{l}\text { Diffusion through inert/ } \\
\text { ash layer (Eq. (20)) }\end{array}$} & \multicolumn{2}{|c|}{$\begin{array}{l}\text { Surface chemical reaction } \\
\text { (Eq. (24)) }\end{array}$} \\
\hline & $K_{m 1}\left(\min ^{-1}\right)$ & $R^{2}$ & $k_{d 1}\left(\min ^{-1}\right)$ & $R^{2}$ & $K_{1}\left(\min ^{-1}\right)$ & $R^{2}$ \\
\hline 5 & 0.0047 & 0.3797 & 0.0037 & 0.9926 & 0.0037 & 0.8929 \\
\hline 10 & 0.0024 & 0.5709 & 0.0020 & 0.9486 & 0.0020 & 0.8776 \\
\hline 70 & 0.0006 & 0.1019 & 0.0005 & 0.9691 & 0.0005 & 0.4447 \\
\hline 100 & 0.0006 & 0.0782 & 0.0004 & 0.9755 & 0.0004 & 0.5011 \\
\hline 150 & 0.0004 & -0.184 & 0.0003 & 0.9075 & 0.0003 & 0.5583 \\
\hline
\end{tabular}

Table 6

Values of the rate constants and regression coefficients for OTC sorption onto the AC(PH-800) (the assumption of the finite volume solution)

\begin{tabular}{|c|c|c|c|c|c|c|}
\hline \multirow[b]{2}{*}{$C_{0}(\mathrm{mg} / \mathrm{l})$} & \multicolumn{2}{|c|}{$\begin{array}{l}\text { Diffusion through liquid film } \\
\text { (Eq. (14)) }\end{array}$} & \multicolumn{2}{|c|}{$\begin{array}{l}\text { Diffusion through inert/ash } \\
\text { layer (Eq. (24)) }\end{array}$} & \multicolumn{2}{|c|}{$\begin{array}{l}\text { Surface chemical reaction } \\
\text { (Eq. (30)) }\end{array}$} \\
\hline & $K_{m 2}\left(\mathrm{~L} \mathrm{mg} \mathrm{\operatorname {min } ^ { - 1 } )}\right.$ & $R^{2}$ & $k_{d 2}\left(\mathrm{~L} \mathrm{mg} \mathrm{\operatorname {min } ^ { - 1 } )}\right.$ & $R^{2}$ & $\left.\overline{K_{2}(\mathrm{~L} \mathrm{mg} \mathrm{min}} \min ^{-1}\right)$ & $R^{2}$ \\
\hline 5 & 0.003400 & 0.9523 & 0.002300 & 0.8244 & 0.002300 & 0.976 \\
\hline 10 & 0.000700 & 0.9968 & 0.000600 & 0.8109 & 0.000500 & 0.9605 \\
\hline 70 & 0.000020 & 0.4856 & 0.000010 & 0.9944 & 0.000010 & 0.6609 \\
\hline 100 & 0.000010 & 0.3224 & 0.000008 & 0.9713 & 0.000009 & 0.8383 \\
\hline 150 & 0.000005 & 0.0682 & 0.000003 & 0.9713 & 0.000003 & 0.5758 \\
\hline
\end{tabular}




\section{Conclusion}

The need for efficient and economic removal of pollutants, namely from aqueous phases, resulted in the development of research on the use of waste materials as precursors for the preparation of less costly AC. The production of activated carbon from peanut's hull with phosphoric acid activation was investigated. The use of such materials can be an efficient alternative for both production of low-cost AC and adoption of effective waste management practices.

The adsorption kinetics of oxytetracycline on derived activated carbon on fixed-bed as a function of the contact time and the initial OTC concentration was investigated. Oxytetracycline adsorption increased for increasing initial OTC concentrations. The equilibrium isotherms of the sorption systems of OTC on $\mathrm{AC}(\mathrm{PH}-$ 800)can be formulated precisely by the Freundlich equation.

A SCM was used; it takes into account the assumption of the finite volume solution. The model was successful in describing the experimental data; while the assumption of infinite volume solution in the SCM can result in erroneous conclusions about the control regime. The adequate fitting of the experimental data values for the whole studied range of concentration, and suggest the applicability of the finite solution volume assumption kinetic model to this sorption system.

\section{References}

[1] A.K. Alegakis, M.N. Tzatzarakis, A.M. Tsatsakis, I.G. Vlachonikolis, V. Liakou, In vitro study of oxytetracycline adsorption on activated charcoal, J. Environ. Sci. Health, Part B 355 (2000) 559-569.

[2] L. Huang, Y. Sun, W. Wang, Q. Yue, T. Yang. Comparative study on characterization of activated carbons prepared by microwave and conventional heating methods and application in removal of oxytetracycline (OTC), Chem. Eng. J. 171 (2011) 1446-1453.

[3] J.M. Dias, M.C.M. Alvim-Ferraz, M.F. Almeida, J. Rivera-Utrilla, M. Sánchez-Polo, Waste materials for activated carbon preparation and its use in aqueous-phase treatment: A review, J. Environ. Manage. 85 (2007) 833-846.

[4] L.S. Chan, W.H. Cheung, S.J. Allen, G. McKay, Error analysis of adsorption isotherm models for acid dyes onto bamboo derived activated carbon, Chin. J. Chem. Eng. 20(3) (2012) 535-542.

[5] W.K. Lafi, Production of activated carbon from acorns and olive seeds, Biomass Bioenergy 20 (2001) 57-62.

[6] Y. Sun, Q. Yue, B. Gao, Q. Li, L. Huang, F. Yao, X. Xu, Preparation of activated carbon derived from cotton linter fibers by fused $\mathrm{NaOH}$ activation and its application for oxytetracycline (OTC) adsorption, J. Colloid Interface Sci. 368 (2012) 521-527.
[7] R. Baccar, M. Sarrà, J. Bouzid, M. Feki, P. Blánquez, Removal of pharmaceutical compounds by activated carbon prepared from agricultural by-product, Chem. Eng. J. 211-212 (2012) 310-317.

[8] Y. Zirui, S. Peldszus, P.M. Huck, Adsorption of selected pharmaceuticals and an endocrine disrupting compound by granular activated carbon, adsorption capacity and kinetics, Environ. Sci. Technol. 43 (2009) 1467-1473.

[9] S. Saha, S.K. Basu, S. DasGupta, Modelling of gassolid reactions of ellipsoidal particles, Indian J. Eng. Mater. Sci. 12 (2005) 37-41.

[10] D. Saqrkar, A. Bandyopadhyay, Shrinking core model in characterizing aqueous phase dye adsorption, Chem. Eng. J. 89 (2011) 69-77.

[11] P.R. Jena, S. De, J.K. Basu, A generalized shrinking core model applied to batch adsorption, Chem. Eng. J. 95 (2003) 143-154.

[12] Y.L. Hwang, G.G. Helfferich, Generalized model for multispecies ion-exchange kinetics including fast reversible reactions, React. Polym. 5 (1987) 237-253.

[13] I. Langmuir, The constitution and fundamental properties of solids and liquids. Part I. solids, J. Am. Chem. Soc. 38 (1916) 2221-2295.

[14] H.M.F. Freundlich, Over the adsorption in solution, J. Phys. Chem. 57 (1906) 385-470.

[15] M. Chabani, K. Akhrib, Y. Ait Ouaissa, A. Amrane, A. Bensmaili Removal of nitrate from drinking water by adsorption using ion exchange resin, Desalin. Water Treat. 24 (2010) 109-116.

[16] O. Levenspiel, Chemical Reaction Engineering, JohnWiley Sons, New York, NY, 1972.

[17] R.O. Ajemba, O.D. Onukwuli, Application of the shrinking core model to the analysis of alumina leaching from ukpor clay using nitric acid, IJERT 1(3) (2012) 2278-0181.

[18] H.J.H. Brouwers, R.J. van Eijk, Reactivity of fly ash: Extension and application of a shrinking core model, Concr. Sci. Eng. 4 (2002) 106-113.

[19] N. Khan, C. Hendrix, J. Hoebus, R. Busson, E. Roets, J. Hoogmartens, Analysis of puried samples of oxytétracycline, 4-epi-oxytétracycline, $\alpha$-apooxytetracycline and $\beta$ apooxytétracycline, Janssen, Chim. Acta 10 (1992) 16-21.

[20] L. Markovska, V. Meshko, V. Noveski, Adsorption of basic dyes in a fixed bed column, Korean J. Chem. Eng. 18(2) (2001) 190-195.

[21] Y. Diao, Activated carbons prepared from phosphoric acid activation of grain sorghum, Bioresour. Technol. 81 (2002) 45-52.

[22] T.L. ter Laak, W.A. Gebbink, J. Tolls, The effect of $\mathrm{pH}$ and ionic strength on the sorption of sulfachloropyridazine, tylosin, and oxytetracycline to soil, Environ. Toxicol. Chem. 25 (2006) 904-911.

[23] Y. Sun, Preparation of activated carbon derived from cotton linter fibers by fused $\mathrm{NaOH}$ activation and its application for oxytetracycline (OTC) adsorption, J. Colloid Interface Sci. 368 (2012) 521-527.

[24] Z. Aksu, E. Kabasakal, Batch adsorption of 2,4dichlorophenoxyacetic acid(2,4-d) from aqueous solution by granular activated carbon, Sep. Purif. Technol. 57 (2003) 1-9.
60 
[25] J.S. Zogorski, S.D. Faust, J.H. Haas Jr, The kinetics of adsorption of phenols by granular activated carbon, J. Colloid Interface Sci. 55 (1976) 329-341.

[26] W. Fritz, E.U. Schlunder, Competitive adsorption of two dissolved organics onto activated carbon, I, adsorption equilibria, Chem. Eng. Sci. 36 (1981) 721730.

[27] W. Fritz, E.U. Schlünder, Competitive adsorption of two dissolved organics onto activated carbon-I, Chem. Eng. Sci. 36 (1981) 731-741. 